\title{
Empirical Analysis and Hypothesis Testing of EWOM on Online Consumer's Purchase Intention
}

\author{
Jing Peng and Xia Li \\ Guangzhou Panyu Polytechnic, Guangzhou, Guangdong 511483, China \\ bjzblm1@163.com
}

Keywords: Internet word of mouth; Purchase Intention; Empirical analysis; Hypothesis testing

\begin{abstract}
In the era of Internet economy, online sales and circulation of products, word-of-mouth marketing has been used by more and more companies as an important marketing method for communicating with customers and promoting sales. The main purpose of this paper is to study the cross-cutting effects of different product types and sources of information, and to explore the relationship between online word of mouth and consumers' purchase intention, analyze the factors that influence consumers' purchase intention, and conduct empirical analysis and hypothesis testing to provide countermeasures and suggestions for product network marketing.
\end{abstract}

\section{Introduction}

With the development of Internet technology, word of mouth is no longer confined to face-to-face communication and communication. Instead, word of mouth, experience, and other related word-of-mouth information are disseminated through the Internet to form a new form of word-of-mouth communication - Internet word-of-mouth. In a virtual environment, due to uncertainty, consumers will shift their trust perceptions of sellers to trust in Internet word-of-mouth. Internet word of mouth has given unique features of social networking, such as facing different individuals, facilitating other consumers to use anonymously at any time and any place, etc[1].This expands the choice of consumers to search for product information and provides other consumers with their own relevant recommendations. Internet word-of-mouth has also received the attention of scholars and business managers and has become a new direction in the field of word-of-mouth marketing research. For most products, consumers cannot try it out in advance. Searching for online word-of-mouth has become an important reference for consumers to purchase. The value of online shopping in this group of information dissemination has received more and more attention. Many e-commerce companies pay more attention to the management and guidance of online word-of-mouth. Internet word-of-mouth has become a new type of marketing tool under the Internet model[2].

Therefore, the research on the impact of online word-of-mouth on consumers' purchase intention is a subject worthy of further discussion. The main purpose of this paper is to explore the cross-cutting effects of different product types and sources of information, and to explore the relationship between online word of mouth and consumers' purchase intentions, and to analyze the factors that influence consumers' willingness to purchase. And conduct empirical analysis and hypothesis testing to provide countermeasures and suggestions for product network marketing.

\section{Brief Description of Basic Concepts}

(1) Characteristics of EWOM. In the traditional word of mouth, there may be only one word-of-mouth recipient at the same time, and the persuasiveness of the word-of-mouth is influenced by the degree of closeness of the relationship between the word-of-mouth sender and the recipient. In Internet word-of-mouth, the sender's comments can persist and pass to an unlimited number of recipients that the sender knows or does not know. In addition, in the online community, the motivation of the person receiving the word-of-mouth communication to understand or trust the communicator is uncertain because they also receive similar or opposite information from other senders[3].Therefore, the manner in which word-of-mouth information is transmitted and consumed 
in the Internet environment significantly affects the role of internet word-of-mouth. The difference between online word of mouth and traditional word of mouth is mainly reflected in these aspects: increase in quantity; dispersion; persistence and observability; valuable and community participation.

(2)Research on Consumers' Purchase Intention Behavior. Consumer behavior refers to consumer behavior of purchasing goods, technology, services, etc. in order to meet their own needs. The most common theoretical framework for analyzing consumer behavior is the study of consumer behavior patterns. From the micro-individual perspective, there are significant differences in consumer behavior. However, when we look at consumer behavior from a macro perspective, we can see that, behind the appearance of different consumer behaviors, there are actually many similarities. After a large number of literature review found that the study of consumer behavior patterns can be divided into three categories: "black box process" theory (Kotler mode), technology acceptance model theory (TAM), rational behavior theory (TRA) research. In fact, the online consumer's purchase intention is essentially the same as the customer's purchase intention under the traditional channels, both of which express the subjective intent of consumers to purchase a certain product or service. However, given the difference between the buying channels and the environment (Internet consumers are using the Internet channel to search for and retrieve product information). The online consumer purchase intention is the tendency of consumers to purchase a certain product or service on the Internet after the consumers retrieve and obtain related information through the Internet[4].Therefore, to study the online consumer's purchase intention must take into account the influence of the network environment.

(3) Factors that affect the spread of EWOM .Internet word of mouth will have different effects on individual consumer behavior. This effect is the Power of e-WOM. It reflects the ability of online word of mouth to change consumer attitudes and behaviors. Internet word of mouth has an impact on consumers' purchase intentions, purchasing behavior, brand awareness, usage evaluation, and product selection, and the size of this influence is influenced by many factors. The factors that will influence the effect of word-of-mouth communication are mainly divided into three categories: sources of information, contents of dissemination, and recipients of information. This classification method is also a classification method commonly used by many scholars. The research model is shown in Fig. 1.

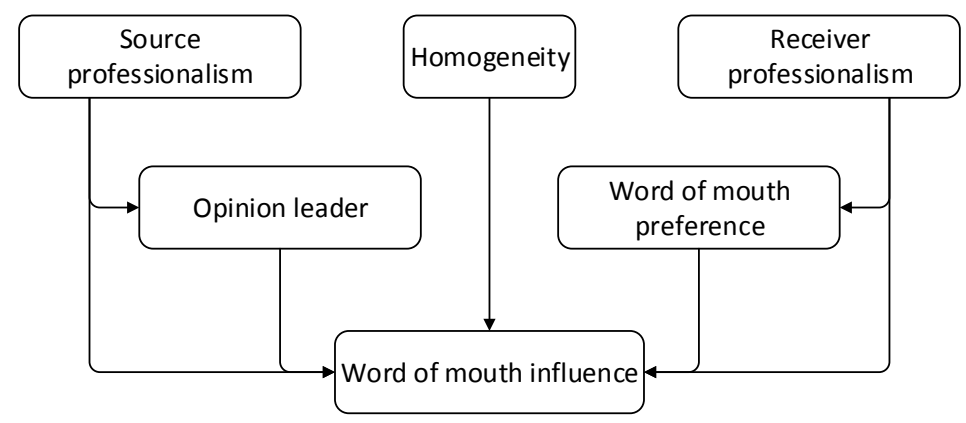

Figure 1. Finite Spread effect model of EWOM.

\section{Research Design of Impact of Internet Word of Mouth on Purchase Intention}

Based on information communication theory, technology acceptance model theory and SOR theory, this paper attempts to build a model of the relationship between online word of mouth and consumers' purchase intention under the cross effect of product type and word of mouth communication platform, and analyzes its internal mechanism of action. Through the literature review of the Internet word-of-mouth dimensions, it can be found that the more commonly used evaluation dimensions are related, vivid, and reliable. Therefore, in the research of Internet word-of-mouth, this paper mainly evaluates the quality of word-of-mouth information from the three dimensions of information relevance, vividness, and reliability[5].This article takes online word of mouth and purchase intention as the research object, and uses product type and information 
source channel as adjusting variables to explore how Internet word of mouth influences consumers' purchase intention in different consumer environments and builds the research model of this paper. From this model, it can be seen that the dimensions of information quality measurement include information relevance, vividness and reliability, and sender factors have a common impact on consumer usefulness and risk perception, ultimately affecting purchase intention. At the same time, product types and source channels regulate the relationship between information quality and sender factors and purchase intention.

(1)Research hypothesis. For the quality of Internet word-of-mouth information, this study proposes the following assumptions:

A1: Positive correlation between online word-of-mouth information quality and consumers' purchase intention

A2: Positive correlation between Internet word-of-mouth information quality and consumer perceived usefulness

A2a: The more relevant the content of word-of-mouth information is, the more useful consumer perception is.

A2b: The more reliable the content of word-of-mouth information, the more useful the perception of consumers

A2c: The more vivid the content of word-of-mouth information, the stronger the usefulness of consumer perception

A3: The quality of Internet word-of-mouth information is negatively correlated with consumer perception risk

A3a: The higher the relevance of word-of-mouth content, the less likely consumers are to perceive risk

A3b: Word of mouth The more reliable the information content, the less likely the consumer is to perceive risk

A3c: The more vivid the word-of-mouth information, the less likely it is that consumers will perceive risk.

For the sender of information, this study proposes the following assumptions:

A4: Online word-of-mouth senders are positively related to consumers' purchase intention

A5: There is a positive correlation between the professionalism of Internet word-of-mouth senders and the usefulness of consumer perception.

A6: The professionalism of Internet word-of-mouth senders is negatively correlated with consumer perceived risk

For perceived usefulness and perceived risk, this study proposes the following assumptions:

A7: Consumer perceived usefulness positively affects their willingness to purchase

A8: Consumer perceived risk negatively affects their willingness to buy

A9: Negative correlation between consumer perceived usefulness and perceived risk

For the moderating effect of product types and source channels on the impact of online word-of-mouth on purchase intentions, this study proposes the following assumptions:

A10: For search products, there are significant differences in the influence of word-of-mouth information from different sources on consumers.

A11: For experiential products, there are significant differences in the influence of word-of-mouth information from different sources on consumers.

(2) Questionnaire design and formation. The major variables involved in this study include information quality, quality of information sources, perceived usefulness, perceived risk, willingness to purchase, product type, and sources of information. At the same time, the quality of Internet word of mouth, the sender of information, the perceived usefulness of consumers, the perceived risk and the validity and validity of purchase intentions, etc., are revised and tested for validity in order to form a formal questionnaire. Through the design of the IWOM, CITC and Cronbach's Alpha test, the scale items are effectively screened, and a total of six dimensions can be formed: relevance, reliability, vividness, sender, perceived risk, perceived usefulness and purchase intention. 


\section{Empirical Analysis of Impact of Internet Word of Mouth on Purchase Intention}

The final questionnaire is based on the measurement items of the EWOM Form. According to the attributes of product types and channel attributes of information sources, based on existing research, interviews were used to identify empirical research objects and data were collected.

(1) Descriptive statistical analysis. The survey mainly focused on young people aged 18 to 28 years. The number of men is 200 , accounting for $48.5 \%$ of the total, and women are 212 , accounting for $51.5 \%$ of the total, indicating that the proportion of men and women surveyed is controlled within a reasonable range. The monthly income of most of the respondents was concentrated in the range of 3,000 to 5,000 yuan and 5000 to 10,000 yuan, indicating that these subjects have a certain degree of economic capacity for online consumption. Therefore, it is easier to get access to relevant online word-of-mouth information, which is exactly what the survey needs. As part of the data analysis of this study, this article uses a certain brand of skin care products as the object of online sales, and uses descriptive statistical analysis, correlation analysis, and hierarchical regression methods to test the aforementioned hypotheses. After the sample pretreatment work, 198 effective samples were obtained. Among all the samples, the proportion of females was greater than that of men, basically in line with the actual situation of the brand skin care products online sales, indicating that the sampling results of this survey were close to reality. In addition, in the number of times the brand skin care products were purchased, the proportion of "less than 3 times" respondents was close to $80 \%[6]$. The sample information from the side explained that the brand skin care product network purchase has not been as popular as clothing and electronic products. There is still room for growth in the buying market.

(2) Reliability analysis. The reliability of this study scale was tested by SPSS 17.0 software. The test results are shown in Table 1 below.

Table 1 The results of reliability analysis

\begin{tabular}{c|cc}
\hline & Variable & Cronbach's a \\
\hline \multirow{7}{*}{ Intensity } & Internet word of mouth dispersion & 0.783 \\
& Internet word of mouth volume & 0.862 \\
& Internet word of mouth rating & 0.767 \\
& Internet word of mouth subjective & 0.731 \\
& Internet word of mouth length & 0.719 \\
& Internet word of mouth credibility & 0.692 \\
& Internet word of mouth purchase intention & 0.726 \\
\hline
\end{tabular}

It can be seen from Table 1 that the correlation coefficient Cronbach's $\alpha$ coefficient is between 0.862 and 0.692 , which is within the acceptable range of reliability, indicating that the scale has good reliability.

\section{Hypothesis test Analysis of Online Word of Mouth Affecting Purchase Intention}

Research shows that individual consumer variables such as gender, education level, and brand preference affect the credibility of online word-of-mouth and purchase intentions. In order to explore the mechanism of Internet word-of-mouth, this article takes gender, educational level, and brand preference as control variables. Because the measured variables have good reliability and validity, the requirements for variable singularity are satisfied. Therefore, we will simplify the above variables (take the mean of all items of the variable as the value of the variable). Table 2 shows the main variables Pearson correlation coefficient, mean and standard deviation. 
Table 2 The peason coefficients, mean and standard deviation between variables

\begin{tabular}{|c|c|c|c|c|c|c|c|c|c|c|}
\hline Variable & 1 & 2 & 3 & 4 & 5 & 6 & 7 & 8 & 9 & 10 \\
\hline 1.First name & 1 & & & & & & & & & \\
\hline 2. Education level & -0.144 & 1 & & & & & & & & \\
\hline 3. Brand favorite & -0.025 & -0.187 & 1 & & & & & & & \\
\hline 4. Quantity & 0.128 & 0.058 & -0.535 & 1 & & & & & & \\
\hline $\begin{array}{l}\text { 5. Word of mouth } \\
\text { dispersion }\end{array}$ & 0.003 & 0.021 & 0.853 & 0.052 & 1 & & & & & \\
\hline $\begin{array}{l}\text { 6. Word of mouth } \\
\text { rating }\end{array}$ & -0.053 & -0.58 & 0.053 & 0.733 & -0.532 & 1 & & & & \\
\hline $\begin{array}{l}\text { 7.Subjective } \\
\text { word-of-mouth ratio }\end{array}$ & -0.059 & 0.075 & -0.525 & -0.392 & 0.293 & 0.429 & 1 & & & \\
\hline $\begin{array}{l}\text { 8. Word of mouth } \\
\text { length }\end{array}$ & -0.085 & -0.066 & -0.834 & 0.042 & 0.845 & -0.428 & 0.039 & 1 & & \\
\hline $\begin{array}{l}\text { 9. Word of mouth } \\
\text { credibility }\end{array}$ & 0.0942 & -0.042 & 0.095 & 0.562 & -0.924 & 0.093 & 0.083 & 0.903 & 1 & \\
\hline 10. Willingness to buy & 0.422 & 0.082 & -0.492 & 0.945 & 0.382 & -0.094 & -0.942 & 0.312 & 0.424 & 1 \\
\hline $\begin{array}{l}\text { Standard } \\
\text { deviation(SD) }\end{array}$ & 0.532 & .734 & 0.349 & 0.894 & 0.854 & 0.764 & 0.729 & 0.601 & 0.489 & 1 \\
\hline
\end{tabular}

Note: $\mathrm{n}=198$;

As can be seen from Table 2, internet word count ( $\mathrm{r}=0.017, \mathrm{p}<0.05)$, Internet word of mouth dispersion $(\mathrm{r}=0.124, \mathrm{p}<0.05)$, Internet word-of-mouth rating $(\mathrm{r}=0.063, \mathrm{p}<0.01)$, and subjective Internet word-of-mouth ratio $(\mathrm{r}=0.112, \mathrm{p}<0.05)$, Word of mouth length $(\mathrm{r}=0.198, \mathrm{p}<0.05)$ is positively related to the purchase intention; The number of Internet word-of-mouth $(\mathrm{r}=0.194$, $\mathrm{p}<0.05)$, the spread of Internet word-of-mouth $(\mathrm{r}=0.107, \mathrm{p}<0.01)$, the length of Internet word-of-mouth $(\mathrm{r}=0.143, \mathrm{p}<0.01)$, and the score of Internet word-of-mouth $(\mathrm{r}=0.056, \mathrm{p}<0.05)$ There is a positive correlation with credibility of Internet word of mouth; The credibility of Internet word of mouth $(r=0.305, p<0.05)$ is positively related to the purchase intention.

\section{Acknowledgment}

This work is supported by the education science planning project of Guangzhou (No.1201554648); Teaching reform project of education teaching steering committee of education in guangdong province (No.CYQN2017072); The ninth batch of education teaching reform project in guangzhou higher school(No.2017F26); University innovation and entrepreneurship education project of Guangzhou(No.201709T35); The "13th five" (first batch) education teaching reform project of Guangzhou Panyu Polytechnic(No.2017JG31).

\section{Conclusions}

Studying the impact of online word of mouth on consumer's purchase intention will not only help enterprises better understand the consumer habits and behaviors of customers' online purchase of goods, but also is of particular concern to e-commerce companies. And help companies recognize the key factors affecting online shopping, so as to improve services and better carry out online word-of-mouth marketing, to increase sales revenue and enhance corporate value.

\section{References}

[1] Cao Qing,Duan Wenjing,Gan Qiwei.Exploring determinants of voting for the "helpful-lness" of online user reviews:A text mining approach[J].Decision Support System,2011,50(2):511521.

[2] Yu Hang,Wang Zhanping.Summary of Research on the Impact of Internet Word of Mouth[J].Journal of Information,2013,32(06):100-106.

[3] Yang Hua, Sun Baofeng, Lin Tianxue, et.al. Research on the Effect of Internet Word of Mouth 
on the Purchase Intention of Consumer Books[J].Library and Information Service, 2018,62(02):117-126.

[4]Pradeep Racher,Wesley Friske.Perceived 'usefulness' of online consumer reviews:An exploratory investigation across three services categories[J].Electronic commerce research and application,2012,11(1/6).

[5] Chen Fajie,Bian Caixiang,Zhou Chunguang.Empirical Research on the Influence of Internet Word of Mouth on Consumers' Willingness to Buy Specialty Agricultural Products[J].Xinjiang Agricultural Economics,2016(10):75-79+92.

[6] Lee Ji.Emerald Article:The difference effects of online consumer reviews on consumers' purchase intentions depending on trust in online shopping malls:An advertising perspe-ctive[J].Internet Research,2011,21(2):187-206. 